\title{
Atherosclerotic disease and risk factor modification in Saudi Arabia: a call to action
}

\author{
This article was published in the following Dove Press journal: \\ Vascular Health and Risk Management \\ 25 May 2012 \\ Number of times this article has been viewed
}

\section{Mohammed Al-Omran \\ The Peripheral Vascular Disease Research Chair and Division of Vascular Surgery, Department of Surgery, College of Medicine, King Saud University, Riyadh, Saudi Arabia}

Correspondence: Mohammed Al-Omran King Khalid University Hospital, Department of Surgery, PO Box 7805(37), Riyadh II472, Saudi Arabia

Tel +96 614 679097

Fax +96614679493

Email malomran@ksu.edu.sa
Purpose: Atherosclerotic disease (AD) is the leading cause of death worldwide and in Saudi Arabia. Intensive risk reduction therapy plays a major role in reducing adverse cardiovascular outcomes in patients with AD. The level of awareness of this important fact amongst physicians (family physicians, general internists, cardiologists and vascular surgeons) in managing these patients in Saudi Arabia is not currently known. This study was conducted to examine the perceptions and knowledge of risk reduction therapy in patients with $\mathrm{AD}$ amongst physicians in Saudi Arabia in two clinical presentations; coronary artery disease (CAD) and peripheral artery disease (PAD).

Materials and methods: We conducted a cross-sectional self-administered survey of 897 physicians at different hospitals in four provinces in Saudi Arabia.

Results: The recommended targets of low density lipoprotein-cholesterol (LDL-C), blood glucose, and blood pressure in patients with CAD and PAD were known as $40 \%$ and $36 \%$; $70 \%$ and $66 \%$; and $32 \%$ and $28 \%$ of physicians, respectively. The initiation of antiplatelet medications, angiotensin converting enzyme (ACE) inhibitors, statins, and nicotine replacement therapy for smokers in patients with CAD and PAD were recommended by $98 \%$ and $97 \% ; 52 \%$ and $34 \% ; 61 \%$ and $56 \%$; and $50 \%$ and $43 \%$ of physicians, respectively. Compared to other specialties, cardiologists had the lowest threshold for initiating risk reduction therapy, whereas vascular surgeons had the highest threshold.

Conclusion: The level of physician awareness of atherosclerosis risk reduction therapy across Saudi Arabia has revealed knowledge and action gaps. A call to action to implement effective strategies to encourage health professionals to use risk reduction therapy and increase public awareness is needed.

Keywords: coronary artery disease, peripheral arterial disease, risk reduction, atherosclerosis

\section{Introduction}

Atherosclerotic disease (AD) is a systemic disease that affects all arterial beds and can present with multiple clinical manifestations according to the end organ supplied, including the heart in coronary artery disease (CAD), and the lower extremities in peripheral artery disease (PAD). Risk factors for AD include male sex, advanced age, cigarette smoking, hypertension, diabetes, and hyperlipidaemia. ${ }^{1}$

Atherosclerotic disease is the leading cause of death worldwide and in Saudi Arabia. ${ }^{2,3}$ In Saudi Arabia, both CAD and PAD are a major public health problem, with an overall prevalence of $5.5 \%{ }^{4}$ and $11.7 \%$ amongst people aged 45 years and older, ${ }^{5}$ respectively. PAD is a marker of advanced atherosclerosis and is associated with an elevated risk of cardiovascular mortality and morbidity; with a 
four-fold increased risk of myocardial infarction ${ }^{6}$ and a two to three-fold increased risk of stroke. ${ }^{7}$ Furthermore, the risk of cardiovascular mortality and morbidity in patients with PAD is comparable to that in patients with CAD. ${ }^{8}$

Reducing the adverse cardiovascular outcomes of atherosclerosis through risk factor identification and modification has been an active area of research over the past few decades. As a result, several large scale randomized clinical trials ${ }^{9-11}$ and observational studies ${ }^{12,13}$ have shown intensive risk reduction therapy to be very effective and critical in reducing adverse cardiovascular outcomes in patients with AD, with many expert international committees recommending the use of risk reduction practices as summarized in Table 1. ${ }^{14-17}$ However, the level of awareness of this information and the implementation of risk factor reduction therapy amongst all physicians is felt to be low, and has been shown to be suboptimal amongst general practitioners, internal medicine specialists, cardiologists, and vascular surgeons in the United States, Canada, and Europe. ${ }^{18-24}$

A small pilot study carried out at a university hospital in Saudi Arabia ${ }^{25}$ showed that there is a knowledge and action gap among physicians with respect to risk factor modification in patients with PAD. However, the knowledge and attitudes of physicians across Saudi Arabia towards risk reduction therapy for patients with AD are not known. Therefore, this study was performed to assess the knowledge of the recommended target levels for blood pressure, blood glucose, and low density lipoprotein-cholesterol (LDL-C), as well as to explore physicians' knowledge and attitudes towards risk reduction therapy in patients with $\mathrm{AD}$. We also examined differences among physicians in the management of these factors in patients with PAD compared to patients with CAD in Saudi Arabia.

\section{Materials and methods}

A self-administered questionnaire was mailed to all family physicians, general internists, cardiologists, and vascular surgeons working at different hospitals in four provinces in Saudi Arabia: central - Riyadh and Qassim; east - Dammam, Khobar, Qatif, Jubail, Hafof, and Hafer Albatin; west Jeddah, Makkah, and Madinah; and south - Abha, Jizan, and Najran. The hospitals were randomly selected and included public, teaching, and private hospitals between March 1, 2009 and February 28, 2010. The questionnaire was based on a previously published and validated questionnaire. ${ }^{25}$ The questionnaire was anonymous and physicians provided consent prior to participation. This study was approved by the King Khalid University Hospital ethics review board, Riyadh, Saudi Arabia.

The survey consisted of multiple choice questions. Participant demographic information was collected, including age, sex, specialty, board certification status, and

Table I Current recommendations of the American Heart Association and American College of Cardiology for risk reduction in patients with coronary artery disease compared to patients with peripheral arterial disease ${ }^{14,16,17}$

\begin{tabular}{|c|c|c|c|c|c|}
\hline & \multirow[t]{2}{*}{ Recommendation } & \multicolumn{2}{|c|}{ Class of recommendation } & \multicolumn{2}{|c|}{ Level of evidence } \\
\hline & & CAD & PAD & CAD & PAD \\
\hline \multicolumn{6}{|l|}{ Medications used } \\
\hline Antiplatelet & All patients & I & I & $A$ & $A$ \\
\hline Statin & All patients & 1 & 1 & B & B \\
\hline \multirow[t]{2}{*}{ ACE inhibitors } & Symptomatic patients & 1 & 1 & $A$ & B \\
\hline & Asymptomatic patients & $2 a$ & $2 a$ & B & B \\
\hline \multicolumn{6}{|l|}{ Goals in managing } \\
\hline \multirow[t]{6}{*}{ Blood pressure } & Systolic & & & & \\
\hline & $<140 \mathrm{mmHg}$ in all patients & 1 & I & A & A \\
\hline & $<130 \mathrm{mmHg}$ in diabetic patients & & & & \\
\hline & Diastolic & & & & \\
\hline & $<90 \mathrm{mmHg}$ in all patients & & & & \\
\hline & $<80 \mathrm{mmHg}$ in diabetic patients & & & & \\
\hline LDL-C & $\mathrm{LDL}<2.5 \mathrm{mmol} / \mathrm{L}$ in all patients & 1 & 1 & A & A \\
\hline Diabetes & $\mathrm{HbA}_{\mathrm{Ic}}<7 \%$ in diabetic patients & 1 & 1 & B & B \\
\hline Smoking & Complete cessation in all patients & 1 & 1 & B & B \\
\hline BMI & $18.5-24.9 \mathrm{~kg} / \mathrm{m}^{2}$ in all patients & I & I & B & B \\
\hline
\end{tabular}

Notes: Class I: Conditions for which there is evidence and/or general agreement that a given procedure or treatment is beneficial, useful, and effective; Class 2: Conditions for which there is conflicting evidence and/or a divergence of opinion about the usefulness/efficacy of a procedure or treatment; Class 2a: Weight of evidence/opinion is in favor of usefulness/efficacy. Level of evidence A: data derived from multiple randomized clinical trials or meta-analyses; Level of evidence B: data derived from a single randomized trial or non-randomized studies.

Abbreviations: AHA/ACC, American Heart Association and American College of Cardiology; CAD, coronary artery disease; PAD, peripheral artery disease; ACE, Angiotensin converting enzyme; LDL-C, low density lipoprotein-cholesterol; HbA ${ }_{1 c}$, glycosylated hemoglobin $A_{I c}$; BMI, body mass index. 
years of experience. All questions were asked with regards to patients with PAD and CAD. The questions aimed to: (1) assess participant knowledge of AD risk factors, including target levels of blood pressure, LDL-C, and blood glucose; and (2) assess participant attitudes towards AD risk reduction therapies. Participants were asked about their attitudes towards: patient counseling of cardiovascular risk reduction; comfort with recommending and instituting risk reduction therapy (smoking cessation, antiplatelet medications, statins, angiotensin converting enzyme [ACE] inhibitors, and antihypertensive medications); factors that influence adequate risk reduction therapy delivery; proportion of patients with PAD or CAD who have their vascular risk factors evaluated systematically; and self-assessment of PAD or CAD risk reduction knowledge.

All survey results were expressed as percentages. The number of respondents who completed each question was used as the denominator for proportions of responses. The prespecified subgroups for comparison analysis of responses to PAD or CAD scenarios were by specialty type - family physicians, general internists, cardiologists, and vascular surgeons. Chi-square tests were used to compare proportions between different subgroups. All $P$-values reported were two-tailed, and values of $P=0.05$ were considered significant.

\section{Results}

529 of the 897 surveyed physicians completed the survey, representing a response rate of $59 \%$. Family physicians, general internists, cardiologists, and vascular surgeons represented $20.2 \%, 41.4 \%, 28 \%$, and $10.4 \%$ of the surveyed physicians, respectively. The results are depicted in Tables $2-5$.

\section{Physicians' characteristics}

Two-thirds of participating physicians were board-certified in their specialties and had been practicing for more than 10 years. Most of the respondents were working in nonacademic institutions (Table 2).

\section{Physicians' knowledge and attitude}

The knowledge of the surveyed participants about the recommended targets of LDL-C, blood pressure, and blood glucose was low for both CAD and PAD, and there was no statistical difference between the knowledge for both entities by specialty (Table 3). Only 38\% knew that an ACE inhibitor can be initiated as an anti-atherosclerotic therapy in PAD patients irrespective of blood pressure status, compared to $46 \%$ for $\mathrm{CAD}(P<0.05)$. Although surveyed cardiologists still showed a knowledge gap in the use of ACE inhibitors for patients with $\mathrm{AD}$, their positive response was statistically higher compared with other specialties $(P<0.05)$. The majority of surveyed physicians indicated that their self-assessment of risk reduction in PAD and CAD (78\% and $77 \%$, respectively) was average to above average. Onethird of surveyed family physicians indicated that their selfassessment of risk reduction knowledge in CAD and PAD (31\% and $30 \%$, respectively) was below average.

Although surveyed physicians' attitudes towards routine risk factor evaluation and associated patient counseling showed a very optimal response, the attitude towards patient assessment for risk factors was suboptimal (Table 4). Apart from routine initiation of antiplatelet therapy ( $98 \%$ for CAD and $96 \%$ for PAD), the attitude towards routine initiation and/ or modification of other risk reduction therapy was very poor, especially for the initiation of ACE inhibitors (52\% for CAD and $34 \%$ for PAD). The surveyed cardiologists were observed to be more likely to initiate different risk reduction therapies when compared to other specialists $(P<0.05)$; however, on the whole, it was still suboptimal. On the other hand, vascular surgeons appeared to have the highest threshold for initiating these therapies; it was, however, only statistically significant for low rates of ACE inhibitor initiation $(P<0.05)$.

Table 2 Characteristics of physicians who completed the survey by specialty $(N=529)$

\begin{tabular}{|c|c|c|c|c|c|}
\hline & $\begin{array}{l}\text { Family physicians } \\
(\mathrm{N}=107)\end{array}$ & $\begin{array}{l}\text { General internists } \\
(N=219)\end{array}$ & $\begin{array}{l}\text { Cardiologists } \\
(N=\mid 48)\end{array}$ & $\begin{array}{l}\text { Vascular surgeons } \\
(\mathbf{N}=55)\end{array}$ & $\begin{array}{l}\text { All } \\
(N=529)\end{array}$ \\
\hline Response rate, \% & 66 & 53 & 53 & 85 & 59 \\
\hline Mean age, $y, \pm S D$ & $43.2 \pm 5.2$ & $39.7 \pm 7.2$ & $38.8 \pm 6.5$ & $39.5 \pm 4.2$ & $40.8 \pm 5.3$ \\
\hline Male sex, \% & 69 & 74 & 74 & 93 & 75 \\
\hline Board-certified, \% & 60 & 56 & 69 & 58 & 61 \\
\hline Academic institute, \% & 33 & 22 & 22 & 16 & 24 \\
\hline \multicolumn{6}{|l|}{ Years in practice } \\
\hline$<5$ years, $\%$ & 19 & 12 & 8 & 17 & 13 \\
\hline $5-10$ years, $\%$ & 25 & 28 & 24 & 15 & 25 \\
\hline$>10$ years, $\%$ & 56 & 60 & 68 & 68 & 62 \\
\hline
\end{tabular}

Abbreviations: $\mathrm{N}$, number; SD, standard deviation. 


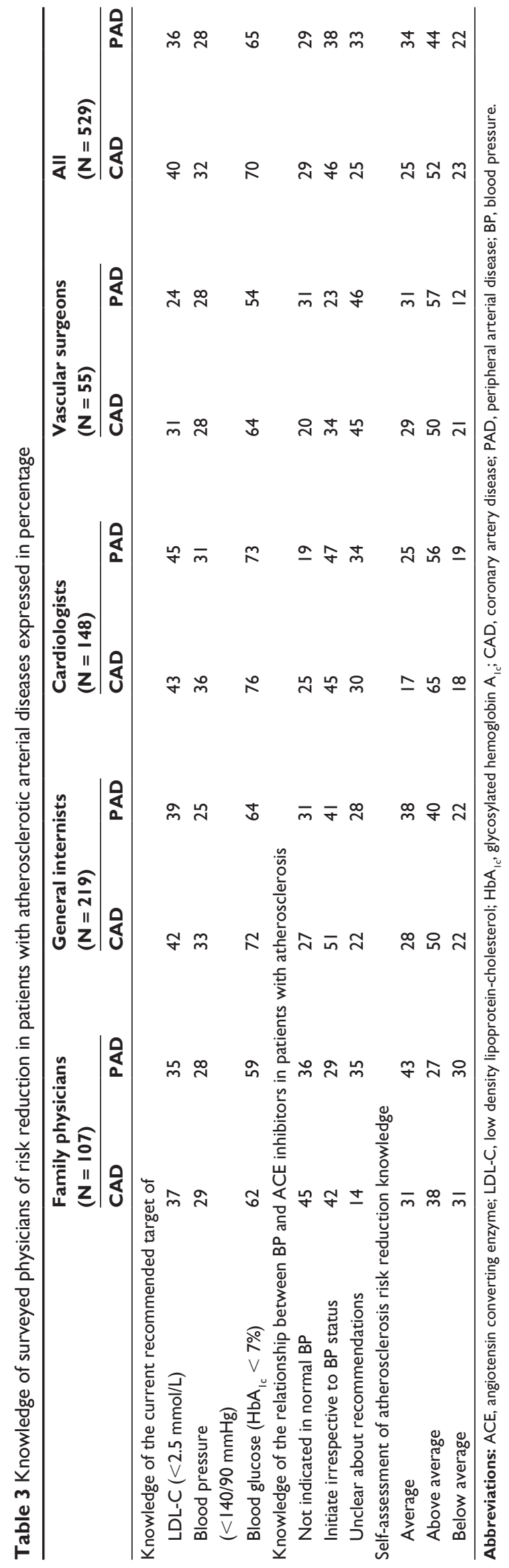

\section{Barriers to the delivery of risk reduction therapy}

The barriers to the delivery of adequate risk reduction therapy are shown in Table 5.

\section{Discussion}

In this study we found that even though the majority of surveyed physicians evaluate and counsel patients with $\mathrm{AD}$ (CAD and PAD) for their risk factors, knowledge and action remain suboptimal, with clear gaps in knowledge identified. The majority of surveyed physicians rated their knowledge about risk reduction as average or above average. However, clear deficiencies in knowledge were identified including: (1) the recommended target levels for blood pressure, blood glucose, and LDL-C; and (2) that ACE inhibitor medications can be used in patients with atherosclerosis irrespective of blood pressure status to reduce atherosclerotic complications and cardiovascular death, with less than half of participants aware of this fact. Furthermore, initiation of all components of risk reduction therapy except antiplatelet medication was poor. The action gap was most prominent amongst family physicians and vascular surgeons when compared to other specialties.

Our findings could be explained by the absence of national or locally adapted guidelines in managing patients with $\mathrm{AD}$, self-audit of practice, and focused continuing medical education programs on risk reduction therapy. Furthermore, suboptimal use of ACE inhibitors could be explained by the fact that the supporting evidence for the use of ACE inhibitors in patients with PAD to reduce the risk of adverse cardiovascular events is not Level A evidence, and is also dependent on the presence of symptoms (ie, class 2a recommendation for symptomatic patients with PAD, and Class $2 b$ recommendation for asymptomatic patients). ${ }^{14}$

Knowledge and action gaps in managing risk factors in patients with AD have also been shown amongst physicians in the United Kingdom, the United States, and Canada. ${ }^{18,22,23,26,27}$ Cassar et al ${ }^{22}$ showed that over a quarter of UK vascular surgeons did not screen for diabetes or measure blood pressure in patients with PAD. For instance, only $34 \%$ of vascular surgeons treated patients with claudication if cholesterol levels were greater than $5.5 \mathrm{mmol} / \mathrm{L}$. McDermott et a ${ }^{18}$ showed that only $45.5 \%$ of internal medicine physicians prescribe antiplatelet medications to patients with PAD compared with $52.5 \%$ of vascular surgeons, and only $16.8 \%$ of vascular surgeons were aware of the large effect of cholesterol lowering on the risk of future 

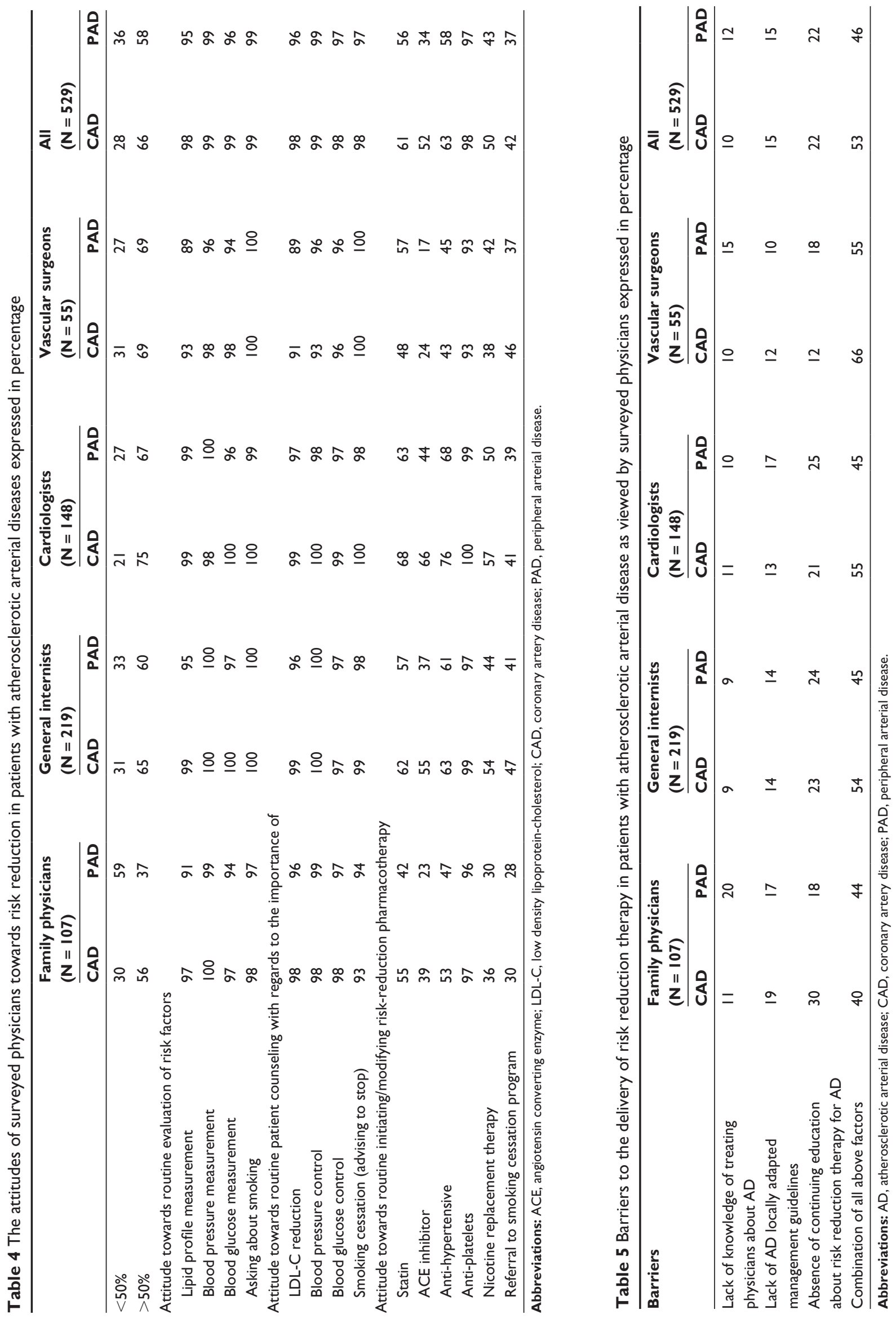
cardiovascular events in patients with PAD compared to $43.6 \%$ of the internal medicine physicians. Furthermore, even amongst cardiologists who were surveyed there were knowledge and action gaps in dealing with atherosclerotic risk. Al-Omran et $\mathrm{al}^{23}$ showed that utilization of risk reduction pharmacotherapy and knowledge of the recommended target levels of blood glucose, blood pressure, and LDL-C levels in patients with PAD amongst Canadian vascular surgeons was suboptimal. Mukherjee et $\mathrm{al}^{26}$ showed a suboptimal use of lifestyle modifications including: smoking cessation; exercise; weight reduction and diet for lipid control; and evidence-based therapy including antiplatelet medications, ACE-inhibitors, beta-blockers, and statins, in patients undergoing peripheral vascular interventions for PAD at hospital discharge and at 6 months follow-up. The knowledge and action gaps in managing risk factors in patients with AD from previously published studies ${ }^{18,22-23,27}$ along with our data, support the fact that there is an international trend of suboptimal use of atherosclerotic risk reduction therapies.

In the evaluation of these results, certain limitations merit emphasis. The validated questionnaire used in this study was based on the 2006 recommendations for secondary prevention. ${ }^{16}$ An update of recommendations has been released in 2011;17 however, there were no major differences in the recommendations that were used in the questionnaire for surveyed physicians. As the data represented self-reported perceptions of knowledge, they may indicate an underestimation of the true knowledge gap that exists. Lastly, the survey form did not differentiate between symptomatic and asymptomatic atherosclerotic disease with regards to the use of ACE inhibitors as a risk reduction therapy.

\section{Conclusion}

In Saudi Arabia there are knowledge and action gaps with regards to $\mathrm{AD}$ risk reduction therapy amongst physicians, despite a considerable effort to evaluate and counsel patients for their risk factors. Given the heightened risk of cardiovascular adverse outcomes in patients with $\mathrm{AD}$, and the fact that AD is the leading cause of death in Saudi Arabia, ${ }^{3}$ the results of this study have important and immediate implications. This study may be used to support a call to action for AD management and provide guidance for targeted interventions including: locally adapted clinical practice guidelines, selfaudit of practice, continuing medical education programs, public awareness campaigns, the inclusion of risk reduction pharmacotherapy as a plenary topic at scientific meetings, and other educational outreach programs that aim to bring physicians' practice into agreement with current guidelines for $\mathrm{AD}$ risk reduction.

\section{Disclosure}

The author reports no conflicts of interest in this work. This paper was presented in part at the 5th Gulf Vascular Surgery Society Conference, Dubai, UAE, February 28-March 1, 2011.

\section{References}

1. Fowkes FG, Housley E, Riemersma RA, et al. Smoking, lipids, glucose intolerance, and blood pressure as risk factors for peripheral atherosclerosis compared with ischemic heart disease in the Edinburgh Artery Study. Am J Epidemiol. 1992;135(4):331-340.

2. World Health Report 2010 [report on the Internet]. What is the deadliest disease in the world? Geneva: World Health Organization; 2010 [updated October 20, 2010; cited March 15, 2012]. Available from: http://www. who.int/features/qa/18/en/. Accessed March 15, 2012.

3. World Health Report 2010 [report on the Internet]. Causes of mortality in Saudi Arabia. Geneva: World Health Organization; 2011 [updated 2011; cited March 15, 2012]. Available from: http://www.who.int/nmh/ countries/sau_en.pdf. Accessed March 15, 2012.

4. Al-Nozha MM, Arafah MR, Al-Mazrou YY, et al. Coronary artery disease in Saudi Arabia. Saudi Med J. 2004;25(9): 1165-1171.

5. Al-Sheikh SO, Aljabri BA, Al-Ansary LA, Al-Khayal LA, Al-Salman MM, Al-Omran MA. Prevalence of and risk factors for peripheral arterial disease in Saudi Arabia. A pilot cross-sectional study. Saudi Med J. 2007;28(3):412-414.

6. Criqui MH, Langer RD, Fronek A, et al. Mortality over a period of 10 years in patients with peripheral arterial disease. $N$ Engl J Med. 1992;326(6):381-386.

7. Wilterdink JL, Easton JD. Vascular event rates in patients with atherosclerotic cerebrovascular disease. Arch Neurol. 1992;49(8): 857-863.

8. CAPRIE Steering Committee. A randomised, blinded, trial of clopidogrel versus aspirin in patients at risk of ischaemic events (CAPRIE). CAPRIE Steering Committee. Lancet. 1996;348(9038): 1329-1339.

9. Antithrombotic Trialists' Collaboration. Collaborative meta-analysis of randomised trials of antiplatelet therapy for prevention of death, myocardial infarction, and stroke in high risk patients. BMJ. 2002; 324(7329):71-86.

10. Yusuf S, Sleight P, Pogue J, Bosch J, Davies R, Dagenais G. Effects of an angiotensin-converting-enzyme inhibitor, ramipril, on cardiovascular events in high-risk patients. The Heart Outcomes Prevention Evaluation Study Investigators. N Engl J Med. 2000;342(3): 145-153.

11. Heart Protection Collaborative Group. MRC/BHF Heart Protection Study of cholesterol lowering with simvastatin in 20,536 highrisk individuals: a randomised placebo-controlled trial. Lancet. 2002;360(9326):7-22.

12. Grover SA, Gray-Donald K, Joseph L, Abrahamowicz M, Coupal L. Life expectancy following dietary modification or smoking cessation. Estimating the benefits of a prudent lifestyle. Arch Intern Med. 1994; 154(15):1697-1704.

13. American Diabetes Association. Position Statement. Standards of medical care for patients with diabetes mellitus. Diabetes Care. 2002;25:S33-S49. 
14. Hirsch AT, Haskal ZJ, Hertzer NR, et al; American Association for Vascular Surgery; Society for Vascular Surgery; Society for Cardiovascular Angiography and Interventions; Society for Vascular Medicine and Biology; Society of Interventional Radiology; ACC/AHA Task Force on Practice Guidelines Writing Committee to Develop Guidelines for the Management of Patients With Peripheral Arterial Disease; American Association of Cardiovascular and Pulmonary Rehabilitation; National Heart, Lung, and Blood Institute; Society for Vascular Nursing; TransAtlantic Inter-Society Consensus; Vascular Disease Foundation. ACC/AHA 2005 Practice Guidelines for the management of patients with peripheral arterial disease (lower extremity, renal, mesenteric, and abdominal aortic): a collaborative report from the American Association for Vascular Surgery/Society for Vascular Surgery, Society for Cardiovascular Angiography and Interventions, Society for Vascular Medicine and Biology, Society of Interventional Radiology, and the ACC/AHA Task Force on Practice Guidelines (Writing Committee to Develop Guidelines for the Management of Patients With Peripheral Arterial Disease): endorsed by the American Association of Cardiovascular and Pulmonary Rehabilitation; National Heart, Lung, and Blood Institute; Society for Vascular Nursing; TransAtlantic InterSociety Consensus; and Vascular Disease Foundation. Circulation. 2006;113(11):e463-e654.

15. Abramson BL, Huckell V, Anand S, et al. Canadian Cardiovascular Society Consensus Conference: peripheral arterial disease - executive summary. Can J Cardiol. 2005;21(12):997-1006.

16. Smith SC Jr, Allen J, Blair SN, et al. AHA/ACC guidelines for secondary prevention for patients with coronary and other atherosclerotic vascular disease: 2006 update: endorsed by the National Heart, Lung, and Blood Institute. Circulation. 2006;113(19):2363-2372.

17. Smith SC, Benjamin EJ, Bonow RO, et al. AHA/ACCF Secondary Prevention and Risk Reduction Therapy for Patients With Coronary and Other Atherosclerotic Vascular Disease: 2011 Update: a guideline from the American Heart Association and American College of Cardiology Foundation. Circulation. 2011;124(22):2458-2473.

18. McDermott MM, Hahn EA, Greenland P, et al. Atherosclerotic risk factor reduction in peripheral arterial disease: results of a national physician survey. J Gen Intern Med. 2002;17(12):895-904.
19. Hirsch AT, Criqui MH, Treat-Jacobson D, et al. Peripheral arterial disease detection, awareness, and treatment in primary care. JAMA. 2001;286(11):1317-1324

20. Hirsch AT, Gloviczki P, Drooz A, Lovell M, Creager MA. Mandate for creation of a national peripheral arterial disease public awareness program: an opportunity to improve cardiovascular health. JVasc Surg. 2004;39(2):474-481.

21. Bhatt DL, Steg PG, Ohman EM, et al. International prevalence, recognition, and treatment of cardiovascular risk factors in outpatients with atherothrombosis. JAMA. 2006;295(2):180-189.

22. Cassar K, Belch JJ, Brittenden J. Are national cardiac guidelines being applied by vascular surgeons? Eur J Vasc Endovasc Surg 2003;26(6):623-628.

23. Al-Omran M, Lindsay TF, Major J, Jawas A, Leiter LA, Verma S. Perceptions of Canadian vascular surgeons toward pharmacological risk reduction in patients with peripheral arterial disease. Ann Vasc Surg. 2006;20(5):555-563.

24. Brown LC, Johnson JA, Majumdar SR, Tsuyuki RT, McAlister FA. Evidence of suboptimal management of cardiovascular risk in patients with type 2 diabetes mellitus and symptomatic atherosclerosis. CMAJ. 2004;171(10):1189-1192.

25. Al-Omran M. Knowledge and attitude of physicians in a major teaching hospital towards atherosclerotic risk reduction therapy in patients with peripheral arterial disease. Vasc Health Risk Manag. 2007;3(6):1019-1027.

26. Mukherjee D, Lingam P, Chetcuti S, et al. Missed opportunities to treat atherosclerosis in patients undergoing peripheral vascular interventions: insights from the University of Michigan Peripheral Vascular Disease Quality Improvement Initiative (PVD-QI2). Circulation. 2002;106(15):1909-1912.

27. McDermott MM, Mandapat AL, Moates A, et al. Knowledge and attitudes regarding cardiovascular disease risk and prevention in patients with coronary or peripheral arterial disease. Arch Intern Med. 2003;163(18):2157-2162.
Vascular Health and Risk Management

\section{Publish your work in this journal}

Vascular Health and Risk Management is an international, peerreviewed journal of therapeutics and risk management, focusing on concise rapid reporting of clinical studies on the processes involved in the maintenance of vascular health; the monitoring, prevention and treatment of vascular disease and its sequelae; and the involvement of

\section{Dovepress}

metabolic disorders, particularly diabetes. This journal is indexed on PubMed Central and MedLine. The manuscript management system is completely online and includes a very quick and fair peer-review system, which is all easy to use. Visit http://www.dovepress.com/ testimonials.php to read real quotes from published authors. 